\title{
Teorías del crecimiento craneofacial: una revisión de literatura
}

\author{
Theories of craniofacial growth: a literature review.
}

Danwill Camargo Prada', Edna Rocío Olaya Gamboa', Ethman Ariel Torres Murillo²

Para citar este artículo: Camargo-Prada D, Olaya-Gamboa ER, Torres-Murillo, EA. Teorías del crecimiento craneofacial: una revisión de literatura. UstaSalud. 2017;16: 78-88

Licencia Creative Commons

\section{(c) (i) (\$) $\Theta$} lo tanto, los lectores pueden acceder libremente a los artículos en su formato .pdf, igualmente podrán descargarlos y difundirlos; sin embargo no podrán modificarlos o alterarlos, adicionalmente se debe reconocer la autoría de las personas que figuran en las publicaciones, pero estas no podrán comercializadas.

\begin{abstract}
1 Especialización en Ortodoncia, Facultad de Odontología, Universidad Santo Tomás, Bucaramanga

2 Grupo de Investigación Salud Integral Bucal (SIB), Universidad Santo Tomás, Bucaramanga
\end{abstract}

Autor de correspondencia: Edna Rocío Olaya Gamboa,

Correo electrónico:

ednaolaya_7@hotmail.com

\section{RESUMEN}

El estudio del crecimiento craneofacial es un proceso complejo y esencial para el diagnóstico y tratamiento de las maloclusiones. La formación de las estructuras craneofaciales se han explicado a lo largo del tiempo por medio de teorías que diferentes investigadores han propuesto en su interés de argumentar sus postulados; así encontramos las teorías de la dominancia cartilaginosa de Scott; Sutural de Sicher; Funcional de Moss; Servosistema de Petrovic; todas reguladas de una u otra manera por la teoría genética. Para hablar de crecimiento y desarrollo es importante comprender que estos dos términos no son sinónimos, pero están muy relacionados. Por crecimiento se entiende el proceso de incremento de la masa de un ser vivo, que se produce por el aumento del número de células (hiperplasia) o de la masa celular (hipertrofia), por otro lado, el desarrollo es el proceso por el cual los seres vivos logran mayor capacidad funcional de sus sistemas a través de los fenómenos de maduración, diferenciación e integración de funciones. En la presente revisión se describen las teorías más importantes del crecimiento craneofacial y los factores que las regulan.

Palabras clave: Crecimiento y desarrollo, maxilares, revisión de literatura.

\section{ABSTRACT}

The study of craniofacial growth is a complex and essential process for the diagnosis and treatment of malocclusions. The formation of craniofacial structures has been explained over time through theories that different researchers have proposed in their interest to argue their postulates; thus we find theories such as Scott's cartilaginous dominance; Sutural Sicher; Functional of Moss; Petrovic Servosystem; All regulated in one way or another by genetic theory. To talk about growth and development it is important to understand that these two terms are not synonymous, but they are very related. Growth is known as the process of increasing the mass of a living being, which is produced by the increase in the number of cells (hyperplasia) or cell mass (hypertrophy). Development is the process by which organisms achieve greater functional capacity of their systems through the phenomena of maturation, differentiation and integration of functions. This review describes the most important theories of craniofacial growth, and the factors that regulate them.

Keywords: Growth and Development, jaws, literature review.
Recibido para publicación: 10 de octubre de 2017. Aceptado para publicación 30 de octubre de 2017 


\section{INTRODUCCIÓN}

El crecimiento y desarrollo craneofacial es un proceso que inicia desde la fecundación y termina con la muerte; es decir, dura toda la vida. Está marcado por una alta influencia genética ${ }^{1,2}$ donde se encuentran unos picos; asociados con los cambios hormonales ${ }^{3}$ que tienen relación con la edad ${ }^{4-6}$. Los términos de crecimiento y desarrollo sin ser sinónimos van de la mano y tienen como objetivo el equilibrio y funcionalidad de todo el sistema estomatognático. El crecimiento se refiere al aumento de las dimensiones corporales, forma y peso que sufre el organismo desde la fecundación hasta la edad adulta o hasta culminar su pico de crecimiento ${ }^{7}$. El desarrollo es el cambio en las proporciones físicas, cambios cuantitativos y cualitativos que tienen lugar en el organismo humano y que traen consigo aumento en la complejidad de la organización e interacción de todos los sistemas ${ }^{5,8}$; tiene como base la diferenciación celular que conduce a la maduración de las diferentes funciones físicas y psíquicas ${ }^{8}$. El crecimiento se basa en la diferenciación y desarrollo previo de un cartílago que puede ser de dos tipos: el cartílago primario, que se caracteriza por tener una influencia genética no guardando una relación con la función, mientras que el cartílago secundario, a pesar de tener similitud con el cartílago primario, posee algunos rasgos propios, como por ejemplo su rol adaptativo que lo relaciona con la función.

Existen varias hipótesis para estudiar el crecimiento y desarrollo craneofacial; publicadas desde la década de 1950 hasta la actualidad ${ }^{7,9}$; si bien es cierto; ninguna se ha considerado completamente válida ${ }^{7}$; han permitido entender mejor los diferentes sitios de crecimiento y su aplicabilidad al manejo temprano de las maloclusiones ${ }^{10}$. Las teorías de crecimiento se encuentran relacionadas con diferentes autores e investigadores, como: James Scott, Harry Sicher, Melvin Moss, Alexandre Petrovic y J.J Mao, entre otros. Para entender mejor estas teorías es importante mencionar que el objetivo de esta revisión es presentar un análisis de las teorías y así hallar las áreas de crecimiento y su relación con el desarrollo de las diferentes maloclusiones y la aplicabilidad clínica.

\section{Teoría dominancia cartilaginosa de James Scott}

James $\mathrm{H}$. Scott ${ }^{11}$ sugirió que las áreas de crecimiento más importantes son las de origen endocondral, asociadas a los cartílagos; y que los factores genéticos intrínsecos presentes en estos cartílagos dirigían el crecimiento craneofacial; de tal modo que la presencia de las sincondrosis en la base de cráneo y su relación con el cartílago del septum nasal son considerados el esqueleto fundamental que dirige la forma y dirección de la cara a nivel fetal. Se explica de igual manera que la separación de los huesos confinada a una sutura puede darse luego de que ocurre el crecimiento de un órgano asociado, tal como el cerebro o el ojo; las suturas para este autor son centros secundarios de crecimiento y bajo la gobernabilidad de los cartílagos. Afirmó además que las porciones cartilaginosas de la cabeza, cápsula nasal, mandíbula y base de cráneo estaban bajo control genético intrínseco, y que continuaban dominando el crecimiento facial posnatal; enfatizó de forma específica cómo el cartílago del tabique nasal durante el crecimiento marcaba el ritmo del crecimiento del maxilar superior y las sincondrosis la dirección y magnitud del crecimiento de la base de cráneo. A continuación se ilustra el papel de las diferentes áreas de crecimiento de acuerdo con esta teoría (Figura 1).

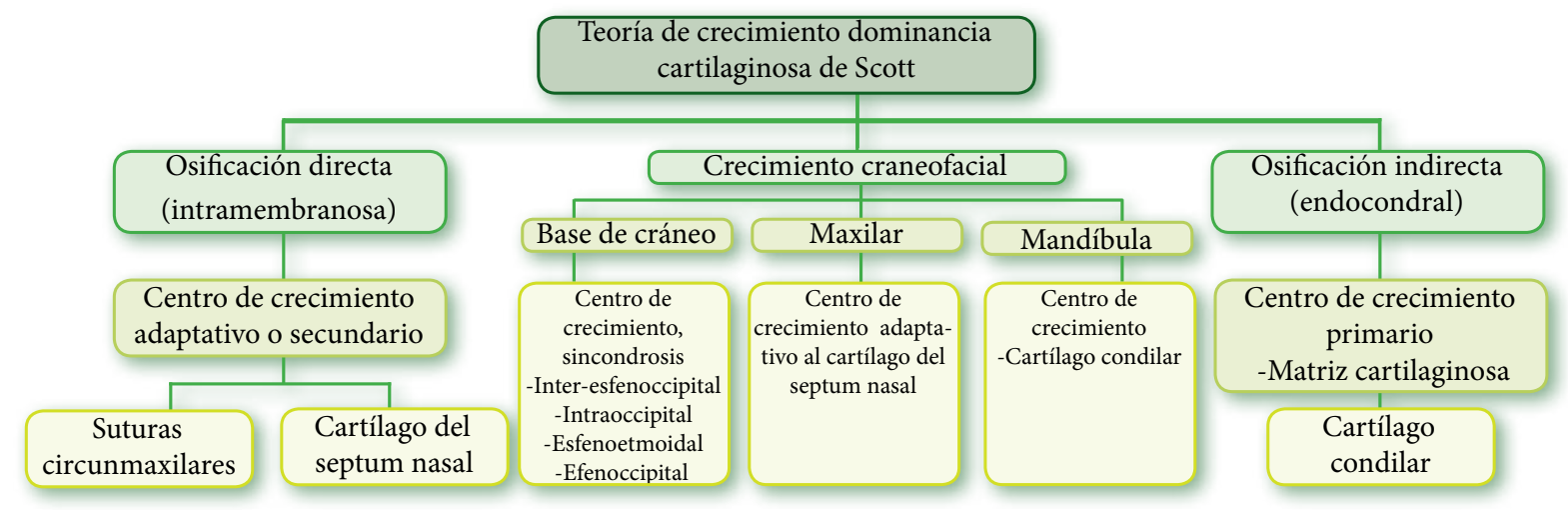

Figura 1. Descripción de la Teoría de crecimiento y dominancia cartilaginosa de Scott. 
Según esta teoría de dominancia cartilaginosa; el crecimiento de la cara humana, en el período posnatal se ubica en dos fases distintas: 1) desde el nacimiento hasta cerca de los 7 años de edad, 2) después del séptimo año ${ }^{11-13}$. Durante la primera fase, el crecimiento es regulado por el cartílago del septum nasal, la base craneal y el cóndilo mandibular. El crecimiento ocurre en las suturas a medida que estas se separan por medio del crecimiento del cartílago del septum nasal y de los contenidos orbitales; el crecimiento sagital maxilar y de bóveda craneal; donde hay un predominio de suturas; es explicado como un desplazamiento secundario al efecto de los cartílagos ${ }^{13}$. La cavidad orbital aumenta de tamaño y el plano de Frankfort no es en este momento un punto de referencia estable. El crecimiento es activo tanto en las regiones craneales como faciales y en el área de unión entre estas regiones; durante este período, la dentición decidua está en uso y los músculos faciales son relativamente más activos y desarrollados que los músculos de la masticación ${ }^{14}$.

Después del séptimo año, concluye el crecimiento del septum nasal y también el crecimiento en las suturas faciales y se marca la influencia del cartílago condilar como centro importante de crecimiento ${ }^{15}$. En esta fase, el crecimiento del esqueleto facial es predominantemente por aposición y remodelado óseo ${ }^{16}$. Sin embargo, los cartílagos del cóndilo mandibular y la sincondrosis esfeno-occipital continúan funcionando como sitios importantes de crecimiento para el empuje del esqueleto facial hacia adelante de la columna vertebral ${ }^{17}$. Los músculos de la masticación alcanzan su desarrollo completo al final de este período al concluir la dentición permanente que varía según la edad cronológica y la edad dental ${ }^{11,18-20}$.

\section{Teoría de dominancia sutural de Harry Sicher y Joseph P. Weinmann}

Para estos autores ${ }^{21}$ los elementos formadores de hueso como las suturas, cartílago y periostio son responsables del crecimiento facial y suponía que todos estaban bajo un fuerte control genético intrínseco. Supuso que la programación intrínseca en las células periósticas productoras de hueso, los cartílagos con vínculo óseo y las suturas de los mismos huesos determinaba el crecimiento, forma y dimensiones óseas. Mientras que influencias como las hormonas y las acciones musculares podrían reforzar estas deter- minantes con predominio genético sin que tuvieran el control del crecimiento. De acuerdo con estudios realizados por Sicher con sustancias colorantes, se demostró que las suturas estaban causando la mayor parte del crecimiento. También se mencionó que el tejido conectivo de las suturas del complejo naso maxilar y la bóveda producían fuerzas que separaban los huesos, tal como las sincondrosis expandían la base craneana y las láminas epifisales elongaban los huesos largos. Por ello la teoría de este autor es considerada como la teoría de la dominancia sutural ${ }^{21}$.

Según Sicher los principales centros de crecimiento siguen un patrón general constante y se hallan en las suturas entre los huesos membranosos del cráneo y los maxilares, junto con los dos puntos de osificación endocondral de la base del cráneo y el cóndilo mandibular'. Por consiguiente, el desplazamiento de la mandíbula se debía a la presión creada por el crecimiento de las suturas, de tal forma que los huesos eran literalmente empujados. Weinmann y Sicher afirmaron que el crecimiento craneofacial como un todo era el resultado de una formación genética innata en los tejidos esqueléticos. Sus ideas llegaron a ser llamadas teoría de la dominancia sutural ${ }^{21}$.

Para lograr tener mejor claridad sobre esta teoría es preciso identificar y mencionar que las suturas están compuestas de 5 capas de tejido entre los márgenes óseos ${ }^{21-22}$ :

1. Dos capas celulares que pertenecen a cada unidad ósea (CAMBIAL).

2. Dos capas fibrosas continuas con un periostio fibroso que cubre cada hueso (Capsular).

3. Una capa central, que contiene vasos sanguíneos y filamentos unidos por fibras de colágeno.

El crecimiento en una sutura ocurre en cada una de las capas celulares (cambiales) y puede diferir en su intensidad y cantidad para cada uno de los huesos.

Esta teoría plantea que el crecimiento del macizo naso-maxilar se debe a cuatro pares de suturas: sutura frontomaxilar, cigomático - maxilar, cigomático - tem- 
poral y pterigopalatina paralelas que unen al cráneo y la cara y empujan el complejo hacia adelante y hacia abajo para adaptar su crecimiento con la mandíbula. La histología de las suturas tiene dos funciones, un sitio óseo de crecimiento activo que es al mismo tiempo la unión entre los huesos vecinos, que permite cierto tipo de movimiento ${ }^{22}$ (Figura 2).

Las articulaciones son sitios de unión de los huesos, las suturas craneales y faciales son articulaciones de tejido conectivo entre los huesos del cráneo, transmiten tensiones mecánicas generadas por medio de la contracción muscular o exógenamente en el trauma durante el nacimiento ${ }^{23}$. Sus efectos son experimentados, observando diferentes parámetros como tensión ósea a nivel del tejido, el filtrado del fluido intersticial que a su vez induce tensión a nivel celular y las respuestas anabólicas o catabólicas ${ }^{24}$. Actualmente los aparatos ortopédicos clínicos ejercen fuerzas estáticas sobre las suturas craneofaciales durante períodos sostenidos de tiempo, permitiendo el crecimiento sutural ${ }^{25,26}$.

\section{Teoría de la matriz funcional de Melvin Moss}

En 1968 Melvin Moss propone una nueva teoría que se opone a la teoría expuesta por Sicher ${ }^{27,28}$. Retoma el concepto funcional del crecimiento craneo- facial propuesto por Klaauw, quien sostenía que la formación del cráneo se daba como resultado de las funciones de los órganos adyacentes ${ }^{28,29}$. Para Moss el cartílago simplemente daba soporte a las estructuras de la nariz, él realizó estudios clínicos en pacientes con ausencia congénita del cartílago del septum nasal; donde el desarrollo facial se daba de manera simétrica y había posiciones normales de los procesos alveolares con desarrollo de la dentición normal, aunque con deformaciones nasales a nivel de la columnela y punta de la nariz ${ }^{27,30}$, de esta manera refuta las teorías basadas en las suturas y cartílagos como centros principales y únicos de crecimiento. Utilizando un método experimental microquirúrgico quiso demostrar el verdadero rol de las suturas en el crecimiento craneofacial, de este modo para comprobar si una estructura es responsable del crecimiento, simplemente se retira y se observa que ocurre con el crecimiento ${ }^{31}$. Fue así como demostró que al extirpar las suturas calvarias, en animales en crecimiento, no se producía disminución en las dimensiones del cráneo neural, lo que lo llevó a afirmar que las suturas no son centros primarios de crecimiento y por el contrario el crecimiento del neurocráneo se debe a una respuesta del crecimiento primario de la masa neural, y las suturas solo son sitios de crecimiento secundario ${ }^{27,31}$.

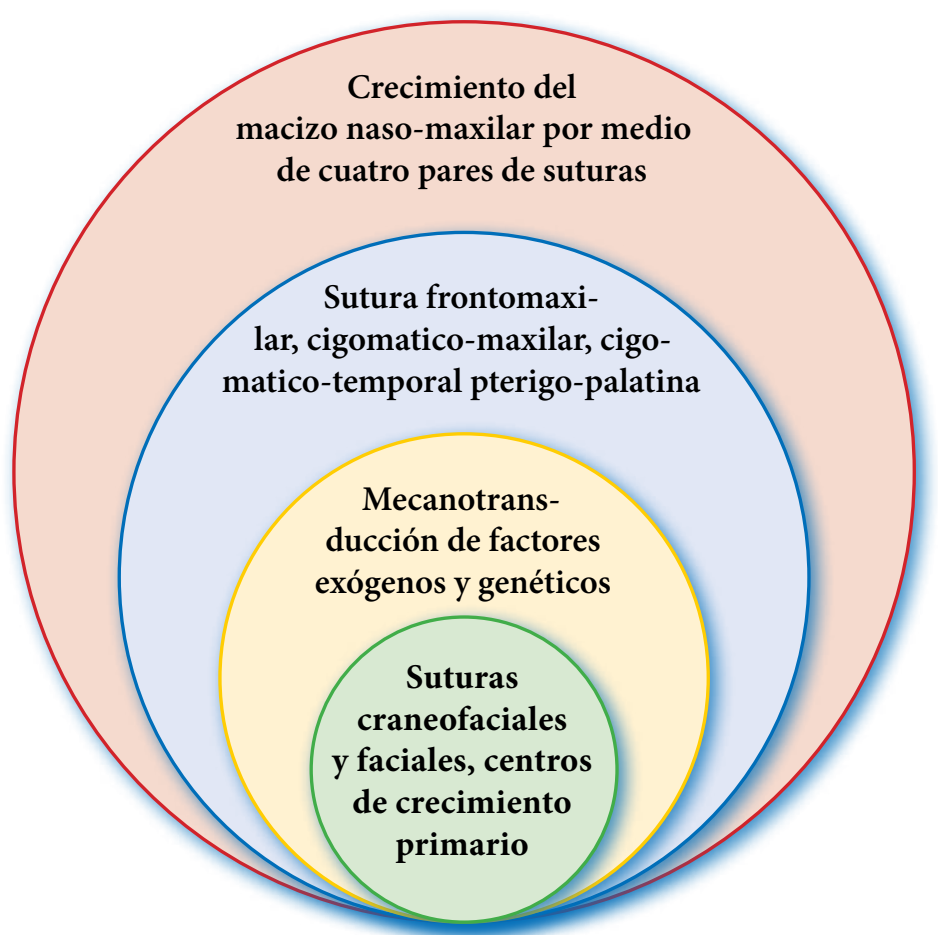

Figura 2. Descripción de la importancia de las suturas en teoría de Sicher. 
Melvin L. Moss introduce el concepto de matriz funcional, quien en esa época prefería denominarlo "Análisis craneal funcional". La Matriz funcional comprende músculos, tejidos blandos, nervios, glándulas, dientes y cavidades que tienen a cargo dicha función y unidades esqueléticas como huesos, cartílagos y tendones que soportan y protegen la matriz ${ }^{27,29-34}$. Para Moss la unidad esquelética (hueso, tendón y cartílago) fue privada de un determinante génico, solo en la etapa embrionaria con los centros de osificación primaria la parte genética tenía influencia, de ahí en adelante la forma dependía de la matriz funcional. Esta teoría describe dos tipos de matriz funcional que determinaban dos tipos de crecimiento, uno de transformación y otro de traslación ${ }^{32}$. La Matriz funcional perióstica actúa directamente sobre la unidad esquelética y es la encargada del remodelado óseo, produciendo un crecimiento directo de transformación ${ }^{33}$. La Matriz funcional capsular responsable de la traslación o de variar la posición en el espacio de las estructuras macro esqueléticas $^{32-34}$ (Figura 3).

Moss en el $1997^{29}$ analiza la hipótesis de la matriz funcional, y la adapta a los nuevos conocimientos. Revisa básicamente dos conceptos: la mecanotransducción celular y la teoría de la red celular biológica. La mecanotransducción se entiende como el proceso mediante el cual las células al ser estimuladas por medio de estímulos mecánicos (mecano-eléctricos, mecano-químicos) generan señales intercelulares que posteriormente van a ser procesadas y producir una respuesta $^{29}$. La matriz extracelular al recibir continuamente cargas estáticas y dinámicas tiende a deformarse y a su vez produce cambios en las células óseas induciéndolas a un proceso de adaptación por medio de la aposición, reabsorción y mantenimiento ${ }^{8}$. Poste- rior a la mecanotransducción celular los espacios intercelulares permiten que la información se transmita de célula a célula, hasta que la información llegue a la matriz perióstica funcional, por lo anterior, se puede afirmar que los espacios de unión entre las células, funcionan como una sinapsis eléctrica, convirtiéndose en una red celular conectada, base de la organización del tejido óseo ${ }^{30}$. A excepción de los osteoclastos todas las células óseas están interconectadas por los espacios de unión, esta red celular ósea conectada permite el paso de señales en ambas direcciones; los osteocitos generan señales de acción por medio de las máculas interconectadas, las células de la cresta neural procesan estos potenciales y jerárquicamente los transmiten hacia arriba para de esta forma regular la respuesta de adaptación de los osteoblastos en la unidad esquelética ${ }^{24}$.

El papel de la mecanotransducción celular dentro de la teoría de la matriz funcional, explica cómo los factores epigenéticos son los responsables de las respuestas adaptativas de los huesos y órganos, en otras palabras, el genoma no regula directamente la respuesta de unidad esquelética, este rol lo desempeña la epigenética, pero a su vez estos dos factores por sí solos no son suficientes para generar el crecimiento, $y$ ambos están directamente relacionados con la ontogénesis. Sin embargo, algunos autores sostienen que la morfogénesis está regulada y dirigida por mecanismos epigenéticos ${ }^{29-34}$.

\section{Teoría del servosistema de Alexandre Petrovic}

Alexandre Petrovic y colaboradores ${ }^{35,36}$, a través de su teoría denominada Servosistema, describen el crecimiento craneofacial, por medio de la influencia

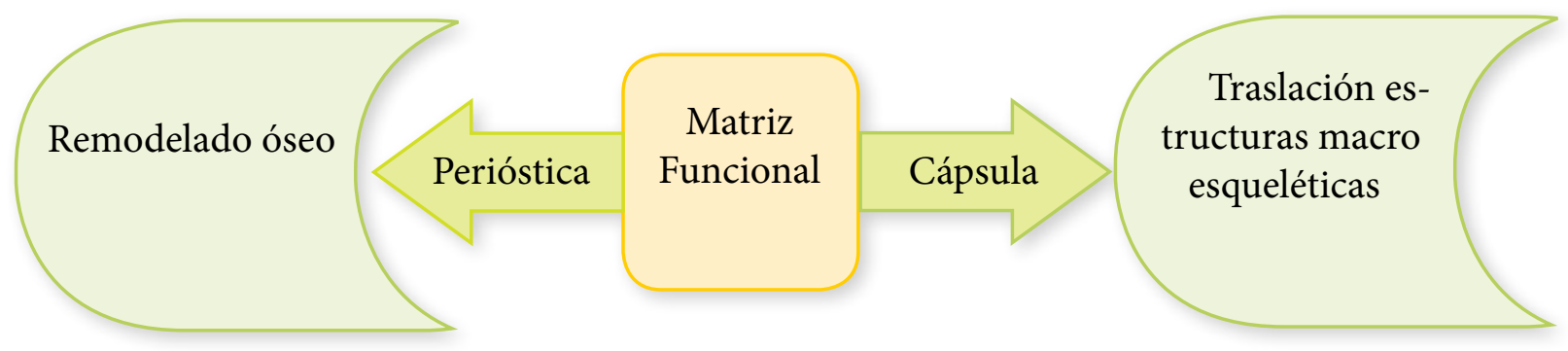

Figura 3. Descripción de la Teoría de la matriz funcional. 
de la carga genética y su expresión condicionada por los estímulos externos que reciba. Petrovic utilizó un lenguaje cibernético para explicar su teoría; para él, el crecimiento craneofacial ocurre por la interacción del mecanismo de aceleración y desaceleración, regulados por otros sistemas de retroalimentación positivos y negativos; en otras palabras, el crecimiento craneofacial se puede concebir como un servosistema que controla automática e inconscientemente el proceso de aposición y reabsorción ósea, dependiendo del estímulo o la información que reciba el sistema. Cabe mencionar que dicha respuesta puede ser modificada por un componente intrínseco facial que involucra aspectos genéticos y hormonales ${ }^{36}$. Para entender mejor la teoría del servosistema, tenemos que asociar algunas estructuras del sistema masticatorio con el lenguaje cibernético, en este orden de ideas, la posición sagital de la arcada superior se considera el referente de entrada al sistema, controlada por la hormona de crecimiento Somatotropina (STH) y somatomedina, el cartílago del tabique y por el crecimiento de la lengua $^{37}$. Por otra parte, la posición sagital del arco inferior, cibernéticamente se considera la variable controlable o comparador periférico ${ }^{36,37}$.

La influencia directa de la STH, somatomedina, sobre el cartílago del septum nasal e indirecta sobre las suturas controlan el crecimiento del maxilar superior, pero además afecta la capacidad de respuesta de los pre-osteoblastos frente a los factores locales y regionales que estimulan su capacidad de división celular ${ }^{12,36-38}$. En el cartílago del septum, la STH y la somatomedina producen un efecto de desplazamiento del maxilar hacia adelante que induce a un crecimiento de la sutura premaxilo-maxilar y en un menor grado a la sutura maxilo-palatina. El maxilar varía su posición, activa mecanismos que inducen al cambio del maxilar inferior, por ende, este proporciona una señal que aumenta la actividad del músculo pterigoideo externo y otros músculos de la masticación, propiciando una óptima posición oclusal, del arco ${ }^{12,36-38}$. El aumento de la actividad muscular induce la proliferación celular en el cartílago del cóndilo, que a su vez estimula una rotación del crecimiento posterior de la mandíbula y posteriormente al crecimiento suplementario del cóndilo. Lo anterior explica la forma como el cóndilo responde a estímulos mecánicos y por consiguiente la manera como la aparatología ortopédica funciona ${ }^{38}$. Existe un comparador central que controla el crecimiento condilar en la teoría del servosistema, que consiste en un engrama regulado por la actividad sensorial de los músculos de la masticación, que proporciona una posición sagital fisiológica del maxilar inferior. La experiencia repetida del posicionamiento del maxilar inferior concomitante con la expresión de señales de corrección para una oclusión óptima son los que forman este engrama muscular ${ }^{39}$. La variación entre las relaciones sagitales de las dos arcadas representa una señal de desviación que automáticamente cambia la actividad del músculo pterigoideo externo, que estimula el crecimiento del cartílago condilar; la posición sagital resultante es lo que definimos como salida del sistema ${ }^{36-38}$.

Básicamente la teoría del servosistema propone lo siguiente:

- El crecimiento del tercio medio de la cara se da a consecuencia del crecimiento de los cartílagos y la sincondrosis del complejo craneofacial, dando como resultado un crecimiento direccionado hacia abajo y hacia adelante ${ }^{12}$.

- Los propioceptores que se encuentran en el ligamento periodontal y en la articulación temporomandibular son mediadores de la alteración postural del maxilar inferior con respecto al maxilar superior, estos propician la activación de los músculos pterigoideo externo y masetero responsables del avance mandibular, por lo tanto el crecimiento del maxilar inferior es controlado por la almohadilla retrodiscal, y el haz inferior del pterigoido externo. La almohadilla retrodiscal al ser estirada, aumenta la vascularización en la región articular, hecho que se convierte en un límite biológico ${ }^{39,40}$.

- El sistema nervioso central es el principal regulador de todo el sistema, ya que en últimas cuentas es quien modula el crecimiento, y por lo tanto se convierte en el comparador central ${ }^{39,40}$.

Con base en los fundamentos de la teoría del servosistema se puede describir la forma como crecen los maxilares. Crecimiento del maxilar superior, influenciado por la STH- somatomedina, la testosterona, y los estrógenos quienes ejercen un efecto directo e indirecto sobre el crecimiento posnatal del maxilar superior. 
El efecto directo se ejercerse en la capacidad de respuesta de los preodontoblastos frente a los factores locales y regionales, ya que estimulan la multiplicación de las células esqueléticas, y el crecimiento de los cartílagos en estructuras como la sincondrosis esfenoccipital, tabique nasal, masas laterales del etmoides y entre el cuerpo y las mayores del esfenoides ${ }^{40}$. El efecto indirecto básicamente se da por la respuesta celular a estímulos, propiciando en sentido longitudinal aposición de la extremidad premaxilar, crecimiento de la sutura premaxilomaxilar y crecimiento de la sutura maxilopalatina. El crecimiento transversal del maxilar superior se da en la sutura interpremaxilar, sutura palatina media $y$ hacia afuera por aposición ósea ${ }^{39,40}$. A partir de estos estímulos mecánicos y esta repuesta ósea un paciente podía convertirse o ser un buen o mal crecedor.

Stutzmann y Petrovic ${ }^{40}$ investigaron la relación que tiene el músculo pterigoideo externo y el frenillo del menisco témporo-mandibular, sobre el crecimiento espontáneo del maxilar inferior estimulado por un hiperpropulsor postural en ratones, y se evidenció que la resección del músculo pterigoideo externo y el frenillo del menisco articular simultáneamente producía disminución en el ritmo del cartílago condilar. Estos resultados corroboran anteriores hallazgos donde la resección del músculo pterigoideo externo no suprime en su totalidad el efecto del estímulo que producen los aparatos funcionales en el crecimiento del maxilar inferior. En conclusión, el crecimiento complementario del maxilar inferior producido por el hiperpropulsor postural no surge solamente del aumento en el ritmo de crecimiento en del cartílago condilar, sino también de las aberturas del ángulo de Stutzmann ${ }^{39,40}$.

Los aparatos funcionales aumentan la contracción del músculo pterigoideo externo e intensifican la actividad repetitiva de la almohadilla retrodiscal, es así como se estimulan los factores de crecimiento y se produce modificación en las trabéculas del cóndilo ${ }^{41}$, que propician un crecimiento adicional del cartílago condilar y una osificación subperióstica adicional del borde posterior del maxilar inferior que se traduce en su alargamiento adicional ${ }^{42}$.

\section{Genética}

El conocimiento, respecto a la complejidad del crecimiento craneofacial y el desarrollo se ha visto refor- zado por los recientes avances en genética y biología molecular. Tres linajes celulares principalmente involucrados en el crecimiento y desarrollo craneofacial son estudiados: osteogénico, condrogénico y fibrogénico. Estos provienen de un progenitor común que son las células mesenquimales ${ }^{43}$ que se originan como resultado de la migración de las células de la cresta neural ${ }^{44,45}$ y para la formación maxilar y mandibular se ubican en los arcos faríngeos ${ }^{46}$. El comportamiento de todas estas células incluye eventos de proliferación, apoptosis, diferenciación y síntesis de las matrices; que son controlados por genes específicos ${ }^{47}$. Los genes pueden ser regulados por aspectos ambientales, incluyendo muchos tipos de estímulos mecánicos; por lo que hoy en día se aplican diferentes aparatologías para estimular estos procesos de diferenciación celular en centros de crecimiento como el cóndilo mandibular ${ }^{48,49}$ y las suturas craneofaciales ${ }^{50}$, la bioingeniería es resultado de estas investigaciones y será el futuro del estudio del crecimiento craneofacial. La genética, la bioingeniería y los métodos biológicos cuantitativos ya han revelado considerables aspectos del crecimiento craneofacial y el desarrollo ${ }^{51,52}$. Van Limborg ${ }^{53}$ muestra cómo estos genes pueden ser influenciados por factores locales y ambientales. La teoría genética es de esta forma controlada por los llamados factores epigenéticos entendidos como modificación en la expresión de genes que no están directamente ligados a una alteración de la secuencia del ADN; es decir, aunque los factores genéticos determinan en gran parte las características de los huesos; existen unos factores externos que logran modificar esos potenciales ${ }^{53,54}$.

Es importante destacar niveles de organización donde se ha visto que pueden regular o modificar este crecimiento, uno de ellos es la matriz extracelular ${ }^{55}$. Esta matriz es determinante en el proceso del crecimiento y desarrollo, y sitio específico donde se generan los diferentes intercambios y expresiones moleculares; un ejemplo de la aplicabilidad a este nivel se observa generando crecimiento en el cóndilo mandibular; en dirección, forma y magnitud, que acaban siendo factores determinantes en la clasificación esquelética clase I, II y III ${ }^{56}$. También se hace énfasis en el papel de la diferenciación celular ${ }^{57}$, mediante la diferenciación celular se determinará el tipo de osificación, llámese intramembranosa o endocondral y a nivel de la osificación intramembranosa se diferenciarán osteoblastos y fibroblastos, osificación 
funcional en suturas. A nivel de la osificación endocondral se diferenciarán osteoblastos y cartílago desarrollados en una matriz cartilaginosa ${ }^{13}$ (Figura 4).

La mecanotransducción es un proceso molecular dinámico que consiste en la transmisión o conversión de fuerzas mecánicas provenientes del medio en señales bioquímicas intracelulares, que producen una respuesta de adaptación celular al medio o bien, llegan hasta expresiones génicas, lo cual depende de las características de la fuerza ${ }^{58}$. Procesos como la remodelación ósea o la pérdida de hueso de soporte dental debido a una oclusión traumática, asociado a un implante; la presencia de hiperplasias o displasias asociadas a zonas de irritación constante; migración de células cancerígenas, la interacción de las células endoteliales con el flujo sanguíneo son ejemplos claros de este mecanismo y conocerlo a fondo ayudará a mejorar los tratamientos para cada caso en particular ${ }^{50}$. Los procesos de mecanotransducción pueden ser: mecanoeléctricos y mecanoquímicos. Los mecanoeléctricos se dan cuando el estímulo llega a células con canales iónicos de voltaje activado y el estímulo pasa a través de la membrana ${ }^{59}$. En los mecanoquímicos las fuerzas físicas son aplicadas a la superficie de células y activan receptores como integrinas y caderinas que proporcionan adhesión celular a la matriz extracelular o entre células vecinas ${ }^{60}$. Estos receptores de adhesión focal al igual que los canales iónicos están conectados al citoesqueleto, siendo este el actor principal en los procesos intracelulares mecanotrasductivos, ya que puede actuar como sensor de las fuerzas físicas aplicadas a la célula, o bien continúa con la transmisión; por lo que presenta una remodelación dinámica de sus componentes, permitiendo a su vez, mantener la arquitectura y biotensegridad celular ${ }^{57,58}$.

\section{CONCLUSIONES}

El crecimiento del complejo craneofacial es un proceso complejo y, por tanto, cada una de las teorías que lo explican aportan de manera complementaria elementos importantes, que permiten en la actualidad su comprensión y aplicabilidad clínica.

La presente revisión de las teorías del crecimiento craneofacial permite concluir que el crecimiento craneal se produce en respuesta al crecimiento del cerebro, concomitante al crecimiento de la base del cráneo que es fundamentalmente un crecimiento endocondral a través de las sincondrosis que tienen un potencial de crecimiento independiente, pero influido por el crecimiento del cerebro. El crecimiento de la sincondrosis y la subsecuente osificación endocondral son casi exclusivamente controlados por los factores genéticos intrínsecos.

El crecimiento del maxilar y de las estructuras asociadas se produce por una combinación del crecimiento a nivel de las suturas y de una remodelación directa de las superficies del hueso, además es probable que este cartílago y los tejidos blandos circundantes contribuyan a la reubicación del maxilar en sentido anterior.

El crecimiento mandibular es endocondral a nivel del cóndilo y de aposición y reabsorción ósea a nivel superficial. Su desplazamiento en el espacio está in-

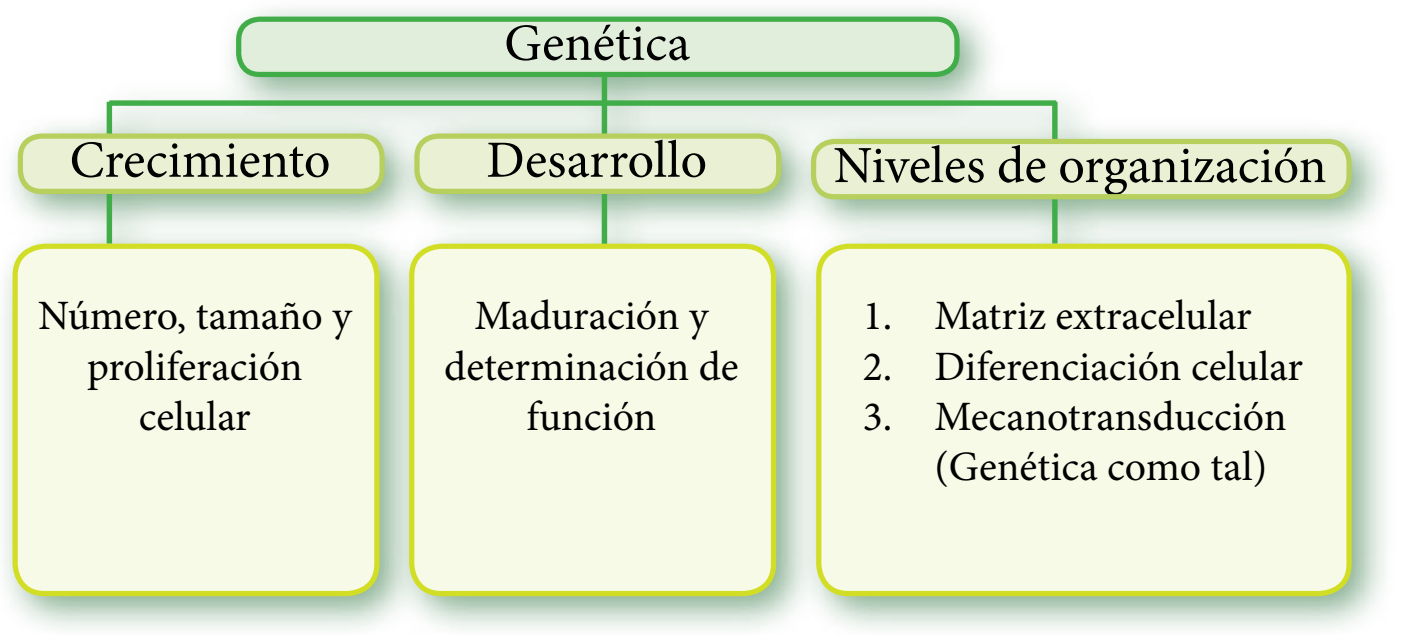

Figura 4. Descripción del papel de la genética en el crecimiento y desarrollo. 
fluenciado por el crecimiento de los músculos y los demás tejidos blandos adyacentes y la adición de hueso nuevo al cóndilo se produce como una respuesta a estimulación exógena. Los procesos intramembranosos de formación ósea pueden ser afectados por los factores ambientales locales, incluso por las fuerzas musculares.

\section{REFERENCIAS}

1. Roosenboom J, Hens G, Mattern BC, Mark S, Claes P. Exploring the Underlying Genetics of Craniofacial Morphology through Various Sources of Knowledge. Biomed Res Int. 2016;20(2):1-9 doi: 10.1155/2016/3054578.

2. Ahmed MK, Ye X, PJ. T. Review of the Genetic Basis of Jaw Malformations. J Pediatr Genet. 2016;5(4):209-19. doi: 10.1055/s-0036-1593505.

3. Litsas G. Growth hormone therapy and craniofacial bones: a comprehensive review. Oral Dis. 2013;19(6):55967; doi: 10.1111/odi.12041.

4. Litsas G1, Ari-Demirkaya A. Growth indicators in orthodontic patients. Part 1: comparison of cervical bone age to hand-wrist skeletal age. Relationship with chronological age. Eur J Paediatr Dent. 2010;11(4):176-80.

5. Andalina E. The Consequences of Cranial-Facial Anomalies [Internet]. Northern Illinois University; 2002 [citado 2017 nov 21]. Recuperado a partir de: http://commons.lib. niu.edu/bitstream/handle/10843/17110/41012SLP Andalina\%2C Elissa Seaver.pdf?sequence=1\&isAllowed $=y$

6. Baccetti T, Franchi L, McNamara J. The cervical vertebral maturation (CVM) method for the assessment of optimal treatment timing in dentofacial orthopedics. Seminars in Orthodontics. 2005;11(3):119-29.

7. Castaldo G, Cerritelli F. Craniofacial growth: evolving paradigms. Cranio. 2015;33(1):23-31. doi: 10.1179/0886963 414Z.00000000042.

8. Singh S, Groves AK. The molecular basis of craniofacial placode development. Wiley Interdiscip Rev Dev Biol. 2016;5(3):363-76. doi: 10.1002/wdev.226.

9. Ranly DM. Craniofacial growth. Dent Clin North Am. 2000;44(3):457-70.

10. Reid RR. Facial skeletal growth and timing of surgical intervention. Clin Plast Surg. 2007;34(3):357-67. doi: 10.1016/j.cps.2007.04.002.
11. Scott JH. The analysis of facial growth from fetal life to adulthood. The Angle Orthodontist. 1963;33(2):110-3.

12. Pritchard JJ, Scott JH, Girgis FG. The structure and development of cranial and facial sutures.TJ Anat. 1956;90(1):73-86.

13. Donnely $\mathrm{H}$ et al. Bone and cartilage differentiation of a single stem cell population driven by material interface. J Tissue Eng. 2017;15(8). doi: 10.1177/2041731417705615.

14. Thilander B, Pena L, Infante C, Parada SS, de Mayorga C. Prevalence of malocclusion and orthodontic treatment need in children and adolescent in Bogota, Colombia. Eur J Orthod. 2001;23:153-67.

15. Copray JC, Jansen HW, Duterloo HS. Growth and growth pressure of mandibular condylar and some primary cartilages of the rat in vitro. Am J Orthod Dentofacial Orthop. 1986;90(1):19-28.

16. Brons S, van Beusichem ME, Bronkhorst EM, Draaisma JM, Bergé SJ, Schols JG, Kuijpers-Jagtman AM. Methods to quantify soft tissue-based cranial growth and treatment outcomes in children: a systematic review. PLoS One. 2014;7(8):24-35. doi: 10.1371/journal.pone.0089602.

17. Rönning O. Basicranial synchondroses and the mandibular condyle in craniofacial growth. Acta Odontol Scand. 1995;53(3):162-6.

18. Scott JH. The shape of the dental arches. J Dent Res. 1957;36(6):996-1003.

19. Demirjan A, Goldstein H, Tanner JM. A new system of dental age assessment. Human Biology. 1973;45(2):211-27.

20. Opperman LA. Cranial sutures as intramembranous bone growth sites. Dev Dyn. 2000;219(4):472-85.

21. Weinmann JP, Sicher H. Bone and bones. Fundamentals of bone biology. 2nd ed. St. Louis MO.: C.v.mosby Co; 1955.

22. Sicher H. Oral Anatomy. 3rd Edition. St. Louis: The C. V. Mosby Co; 1970.

23. Marks SC Jr, Odgren PR, Popoff SN, Wurtz T. Sutures, growth plates and the craniofacial base--experimental studies in the toothless (tl-osteopetrotic) rat. Ann Acad Med Singapore. 1999;28(5):650-54.

24. Opperman LA, Rawlins JT. The extracellular matrix environment in suture morphogenesis and growth. Cells Tissues Organs. 2005;181(3-4):127-35. 
25. Perinetti G, Primožič J, Franchi L, Contardo L. Treatment Effects of Removable Functional Appliances in Pre-Pubertal and Pubertal Class II Patients: A Systematic Review and Meta-Analysis of Controlled Studies. PLoS One. 2015;28(10): doi: 10.1371/journal.pone.0141198.

26. Baccetti T. Improving the effectiveness of functional jaw orthopedics in Class II malocclusion by appropriate treatment timing. Orthod Fr. 2010;81(4):279-86. doi: 10.1051/ orthodfr/2010026.

27. Moss ML, Rankow RM. The role of the functional matrix in mandibular growth. Angle Orthod. 1968;38(2):95-103.

28. Moss ML. The role of muscular functional matrices in development and maintenance of occlusion. Bull Pac Coast Soc Orthod. 1970;45(4):29-30.

29. Moss ML. The functional matrix hypothesis revisited. 1. The role of mechanotransduction. Am J Orthod Dentofacial Orthop. 1997;112(1):8-11.

30. Moss ML. The functional matrix hypothesis revisited. 2. The role of an osseous connected cellular network. Am J Orthod Dentofacial Orthop. 1997;112(2):221-6.

31. Moss ML. Twenty years of functional cranial analysis. Am J Orthod. 1972;61(5):479-85.

32. Moss ML. The functional matrix hypothesis revisited. 3. The genomic thesis. Am J Orthod Dentofacial Orthop. 1997;112(3):338-42.

33. Moss ML. The functional matrix hypothesis revisited. 4 . The epigenetic antithesis and the resolving synthesis. Am J Orthod Dentofacial Orthop. 1997;112(4):410-7.

34. Moss ML. The differential roles of periosteal and capsular functional matrices in oro-facial growth. Rep Congr Eur Orthod Soc. 1969:193-205.

35. Stutzmann JJ, Petrovic AG. Role of the lateral pterygoid muscle and meniscotemporomandibular frenum in spontaneous growth of the mandible and in growth stimulated by the postural hyperpropulsor. Am J Orthod Dentofacial Orthop. 1990;97(5):381-92.

36. Petrovic AG, Stutzmann JJ, Oudet CL. Control processes in postnatal growth of mandibular condyle cartilage. Rev Iberoam Ortod. 1986;6(1):11-58.

37. Petrovic AG, Stutzmann JJ. Reactive capacity of animal and human condylar cartilage at the cellular and molecular levels in the light of a cybernetic concept of facial growth. Fortschr Kieferorthop. 1988;49(5):405-25.
38. 38. Petrovic AG, Stutzmann JJ, Shambaugh GE Jr. Experimental studies on pathology and therapy of otospongiosis. Am J Otol. 1985;6(1):43-50.

39. Obwegeser HL. Clinical Experience Regarding the Influence of the Condyle on the Growth of the Mandible. In: Mandibular Growth Anomalies. Berlin, Heidelberg: Springer Berlin Heidelberg; 2001 [cited 2017 Nov 21]. p. 49-135.

40. Stutzmann JJ, Petrovic AG, George D. Effect of active retrodisplacement on the growth of the mandible in young rats. Role of the pterygoid muscle and elastic menisco-temporal frenum on the rate and direction of condylar growth. Orthod Fr. 1976;47(0):1-14.

41. Hourfar J, Lisson JA, Gross U, Frye L, Kinzinger GSM. Soft tissue profile changes after Functional Mandibular Advancer or Herbst appliance treatment in class II patients. Clin Oral Investig [Internet]. 2017 [citado 2017 ago 10];1-9 [9 p. aprox.]. Recuperado a partir de: https://link. springer.com/article/10.1007\%2Fs00784-017-2177-0. doi:10.1007/s00784-017-2177-0.

42. Kozak FK, Ospina JC. Characteristics of Normal and Abnormal Postnatal Craniofacial Growth and Development. In: Flint PW et al., editor. Cummings Otolaryngology Head and neck surgery [Internet]. 6th edition. Elsevier; 2014 [citado 2017 nov 21]. Recuperado a partir de: https://clinicalgate.com/characteristics-of-normal-and-abnormal-postnatal-craniofacial-growth-and-development/

43. Owtad P, Potres Z, Shen G, Petocz P, Darendeliler MA. A histochemical study on condylar cartilage and glenoid fossa during mandibular advancement. Angle Orthod. 2011;81(2):270-6. doi: doi: 10.2319/021710-99.1.

44. Neirinckx V, Coste C, Rogister B, Wislet-Gendebien S. Concise review: adult mesenchymal stem cells, adult neural crest stem cells, and therapy of neurological pathologies: a state of play. Stem Cells Transl Med. 2013;2(4):28496. doi: 10.5966/sctm.2012-0147.

45. Vega-López GA, Cerrizuela S, Aybar MJ. Trunk neural crest cells: formation, migration and beyond. Int J Dev Biol. 2017;61(1):5-15. doi:0.1387/ijdb.160408gv.

46. Furutera T, Takechi M, Kitazawa T, Takei J, Yamada T, $\mathrm{Vu}$ Hoang $\mathrm{T}$ et al. Differing contributions of the first and second pharyngeal arches to tympanic membrane formation in the mouse and chick. Development. 2017;144(18):3315-3324 doi: 10.1242/dev.149765.

47. Alhadlaq A, Mao JJ. Mesenchymal stem cells: isolation and therapeutics. Stem Cells Dev. 2004;13(4):436-48. doi: 10.1089/scd.2004.13.436. 
48. Ward BB, Brown SE, Krebsbach PH. Bioengineering strategies for regeneration of craniofacial bone: a review of emerging technologies. Oral Dis. 2010;16(8):709-16. doi: 10.1111/j.601-0825.2010.01682.x.

49. Hinton RJ. Genes that regulate morphogenesis and growth of the temporomandibular joint: a review. Dev Dyn. 2014;243(7):864-74. doi:10.1002/dvdy.24130.

50. Lattanzi W, Barba M, Di Pietro L, Boyadjiev SA. Genetic advances in craniosynostosis. Am J Med Genet A. 2017;173(5):1406-29. doi:10.002/ajmg.a.38159.

51. Kim SG, Zhou J, Solomon C, Zheng Y, Suzuki T, Chen $\mathrm{M}$ et al. Effects of growth factors on dental stem/progenitor cells. Dent Clin North Am. 2012;56(3):563-75. doi: 10.1016/j.cden.2012.05.001.

52. Freire M, Choi JH, Nguyen A, Chee YD, Kook JK, You HK et al. Application of AMOR in craniofacial rabbit bone bioengineering. Biomed Res Int [Internet]. 2015 [citado 2017 feb 5];1-7 [7 p. aprox.]. doi: 10.1155/2015/628769.

53. van Limborgh J. The role of genetic and local environmental factors in the control of postnatal craniofacial morphogenesis. Acta Morphol Neerl Scand. 1972;10(1):37-42.

54. Hall BK. Genetic and epigenetic control of connective tissues in the craniofacial structures. Birth Defects Orig Artic Ser. 1984;20(3):1-17.
55. Ishibashi H, Takenoshita Y, Ishibashi K, Oka M. Expression of extracellular matrix in human mandibular condyle. Oral Surg Oral Med Oral Pathol Oral Radiol Endod. 1996;81(4):402-14.

56. Wang L, Detamore MS. Tissue engineering the mandibular condyle. Tissue Eng. 2007;13(8):1955-71. Doi: 10.1089/ten.2006.0152.

57. Anasiz Y, Ozgul RK, Uckan-Cetinkaya D. A New Chapter for Mesenchymal Stem Cells: Decellularized Extracellular Matrices. Stem Cell Rev. 2017;13(5):587-597. doi: 10.1007/s12015-017-9757-x.

58. Maycas M, Esbrit P, Gortázar AR. Molecular mechanis$\mathrm{ms}$ in bone mechanotransduction. Histol Histopathol. 2017;32(8):751-60. doi: 10.14670/HH-11-858.

59. Skerry TM. The response of bone to mechanical loading and disuse: fundamental principles and influences on osteoblast/osteocyte homeostasis. Arch Biochem Biophys. 2008;15(473):117-23. doi: 10.1016/j.abb.2008.02.028.

60. Grad S, Eglin D, Alini M, Stoddart MJ. Physical stimulation of chondrogenic cells in vitro: a review. Clin Orthop Relat Res. 2011;469(10):2764-72. doi:10.1007/ s11999-011-1819-9. 